\title{
Ese espejismo de dos caras: estrategias de la modernización cultural en Venezuela (siglo XIX)
}

\author{
That Two-Faced Mirage: Cultural Modernization \\ Strategies in Venezuela (19 ${ }^{\text {th }}$ Century) \\ Essa miragem de duas faces: estratégias da modernização \\ cultural na Venezuela (século XIX)
}

\section{Paulette Silva Beauregard}

UNIVERSIDAD SIMÓN BOLÍVAR, CARACAS, VENEZUELA

Profesora titular de la Universidad Simón Bolívar, Caracas, y doctora en

Letras de la misma Universidad. Ha publicado Una vasta morada

de enmascarados: poesía, cultura y modernización en Venezuela a

finales del siglo XX (Caracas: La Casa de Bello, 1993), De médicos, idilios y otras historias: relatos sentimentales y diagnósticos de fin de siglo. 1880-1910 (Bogotá: Universidad de Antioquia/Convenio Andrés Bello, 200o; Premio Pensamiento Latinoamericano 2000) y Las tramas de los lectores: estrategias de la modernización cultural en Venezuela (Caracas: Fundación para la Cultura Urbana, 2007;

Premio de la misma fundación 2007), además de artículos en libros y revistas especializadas. Correo electrónico: psilva@usb.ve

\footnotetext{
Artículo de reflexión

Este artículo corresponde, con algunas pequeñas modificaciones, al capítulo inicial del libro Las tramas de los lectores (Fundación de la Cultura Urbana, 2007). Forma parte, asimismo, de una investigación sobre la circulación de impresos e ideas y la ampliación del público lector en la cultura venezolana del siglo XIX. Documento accesible en línea desde la siguiente dirección: http://revistas.javeriana.edu.co
} 


\section{Resumen}

El trabajo intenta revisar algunos temas ligados a la ampliación del público lector y a las prácticas y sociabilidades que estaban en juego en los proyectos letrados venezolanos del siglo XIX. Se detiene, por tanto, en los usos que los escritores hicieron de los medios y nuevos formatos que tuvieron a su alcance, al tiempo que examina algunos casos concretos, referidos a momentos decisivos en la circulación de los impresos (la introducción de la imprenta, la apropiación de géneros modernos como el folletín o la adopción de técnicas de reproducción de imágenes), que permitan mostrar la complejidad de estos problemas $\mathrm{y}$ algunas vías para acercarse a ellos.

Palabras clave: historia de la lectura; siglo XIX; circulación de libros e ideas; democratización; modernidad

\section{Abstract}

This work tries to review some topics associated to the growth of the reading public and the practices and sociabilities that were at stake in the Venezuelan literacy projects of the 19th Century. Thus, it focuses on the uses that writers made of the new media and formats that they could have access to, while also examining some concrete cases. These refer to decisive moments for the circulation of printed documents (the introduction the printing press, the appropriation of modern genres such as the melodramatic novel, or the adoption of image reproduction techniques) which allowed to show the complexity of the aforementioned problems and some ways to approach them.

Keywords: history of reading; $19^{\text {th }}$ century; book and idea circulation; democratization; modernity

\section{Resumo}

O trabalho objetiva rever algumas questões relacionadas à expansão do público leitor e as práticas e sociabilidades em jogo nos projetos letrados venezuelanos do século XIX.

Detém-se, portanto, nos usos que os escritores fizeram da mídia e novos formatos que tiveram a disposição, ao tempo que examina casos concretos, referidos a momentos decisórios na circulação dos impressos (a introdução da prensa, a apropriação de géneros modernos como o folhetim ou a adopção de técnicas de reprodução de imagem), que permitam mostrar a complexidade destes problemas e algumas vias para se aproximar deles.

Palavras-chave: história da leitura; século XIX; circulação de livros e ideias; democratização; modernidade

\section{Cómo citar este artículo:}

Silva Beauregard, Paulette. "Ese espejismo de dos caras: estrategias de la modernización cultural en Venezuela (siglo XIX)". Cuadernos de Literatura 20.39 (2016): 95-114. http://dx.doi.org/10.11144/Javeriana.cl20-39.edce 


\begin{abstract}
"La modernidad, ese espejismo de dos caras que sólo se hace realidad cuando ha quedado atrás y siendo antiguo permanece"
\end{abstract}

AUgusto MONTERROSO. Pájaros de Hispanoamérica

EN MUCHOS ESTUDIOS sobre el siglo XIX latinoamericano se da por sentado un número tan grande de conceptos, que se ha llegado a forzar las manifestaciones culturales y literarias de esa época para que se adapten a una visión actual. Al trabajar, por ejemplo, fundamentalmente con "obras" $y$ "autores" se ha acabado por olvidar que muchas de las nociones empleadas hoy con tanta naturalidad y con la certeza de que tienen un significado claro, fijo, estaban en pleno proceso de cambio, de reacomodo, y que solo después de muchos ajustes, tanteos y fracasos, marchas y contramarchas, se llegó a formularlos como los entendemos en la actualidad. Es el caso de los conceptos de letras, literatura, artista, letrado y escritor, para solo mencionar algunos términos importantes para este trabajo. Tampoco se recuerda que el campo cultural es un inestable terreno de lucha y que tales nociones fueron también el resultado del esfuerzo realizado por generaciones de escritores por vivir de su trabajo, esto es, por profesionalizarse. La aspiración de construir una literatura nacional que caracterizó a los estudios literarios desde el siglo XIX, terminó por aislar "obras" y "autores" de los proyectos de los que formaron parte, fundamentalmente ligados a medios, como el periódico, que ya apuntaban a fenómenos de masa, aunque fuese de un modo todavía incipiente.

Colocar en el centro de la mira asuntos ligados a los lectores, el trabajo efectivo de los "autores", las prácticas y sociabilidades que estaban en juego en los proyectos letrados del siglo XIX y los usos que los escritores hicieron de los medios y nuevos formatos que tuvieron a su alcance (la imprenta, el periódico, el folletín, el melodrama, los grabados y fotografías), fueron los motivos que han animado mi investigación. Para lograr un cambio de perspectiva que permitiera un acercamiento a esos problemas fue fundamental aprovechar los estudios sobre la historia de la lectura que han aparecido en las últimas décadas. Sin embargo, debo decir que el tema no ha resultado muy atractivo en Hispanoamérica, razón por la cual los trabajos consultados se refieren fundamentalmente a Europa, lo que no deja de ser un grave problema ${ }^{1}$. Efectivamente, en las investigaciones sobre la

1 Mi intención ha sido, entonces, valerme de algunas propuestas realizadas por los estudios sobre la lectura (Chartier Entre poder y placer: cultura escrita y literatura en la Edad Moderna, Darnton "Historia de la lectura", Wittmann, Lyons y De Certeau "Leer: una cacería furtiva" y La escritura de la historia, entre otros) para examinar algunos aspectos relacionados con los lectores, los escritores y la circulación de impresos en Venezuela durante el siglo XIX. Entre los 
lectura ha predominado una mirada eurocéntrica en la que, aunque resulte paradójico, la misma España ha sido entendida como un territorio marginal, para no hablar de las que fueron sus colonias. Así, el volumen colectivo coordinado por G. Cavallo y R. Chartier lleva un título tan ambicioso, Historia de la lectura en el mundo occidental, que termina por decepcionar cuando se constata que los trabajos se refieren sobre todo a Alemania, Estados Unidos, Francia e Inglaterra, aunque en el aporte de Chartier ("Lecturas y lectores 'populares'...") sobre los lectores populares en la época del Renacimiento hay referencias a casos españoles. Así mismo, los libros más recientes que se han ocupado de España ignoran los territorios fuera de la península, a pesar de que abarcan períodos tan amplios que deberían haber obligado a revisar los intercambios que existieron con las colonias. Este es el caso, por ejemplo, del volumen colectivo coordinado por Botrel, Infantes y López que lleva por título curiosamente Historia de la edición y de la lectura en España: 1472-1914. Y digo curiosamente porque no hay capítulos dedicados a los territorios americanos, a pesar de que el período a considerar se inicia poco antes del descubrimiento de América.

El examen de estos trabajos me obligó a detenerme en un problema que no había podido abordar con anterioridad a pesar de la importancia que creía que tenía. Me refiero a la periodización de las manifestaciones culturales en Hispanoamérica. Los estudios sobre la lectura han intentado dar respuesta a una pregunta que no ha podido responderse con claridad, esto es, si hubo una revolución en la lectura en Europa durante el siglo XVIII. El énfasis ha sido puesto entonces en esa centuria, lo que ha permitido entender las muchas transformaciones ocurridas en esa época. Los estudios hispanoamericanos, en contraste, centrados fundamentalmente en el letrado - ahora también en la escritora- y sus obras, se han ocupado sobre todo del siglo XIX (tal vez juegue un papel decisivo en que haya sido de ese modo el hecho de que a comienzos de esa centuria se inicia el período republicano). Quizá prolongando la visión que se impuso con la independencia, la colonia sigue pareciendo pobre o poco atractiva. Las investigaciones hispanoamericanas han privilegiado la época modernista en la que se supone que se dan los cambios más radicales vinculados al proceso de autonomización de la literatura y de la profesionalización del escritor. Por lo común se cree que el escritor se profesionaliza fundamentalmente porque se reconoce a sí mismo como artista (los manifiestos y textos ficcionales del modernismo que

pocos estudios que han revisado el tema en América Latina en los últimos años, deben mencionarse los trabajos de Poblete, Catelli y Zanetti, así como el libro colectivo sobre la historia de la lectura en México, publicado por primera vez en 1988. 
reflexionan sobre el escritor y el estilo han sido indicios claros de esa transformación), pero olvidamos que a todo lo largo del siglo hubo un esfuerzo sostenido de muchos letrados por vivir de la pluma, para lo cual apelaron a muy diversas estrategias y echaron mano de formatos o géneros exitosos en Europa, como el folletín.

La concepción de la escritura como un trabajo por el cual se debe recibir una remuneración y la consideración de la autoría como un derecho de propiedad sobre las obras no aparecen repentinamente en la segunda mitad del siglo XIX. En "Lectores, escritores y redactores: prácticas de lectura y escritura en Caracas a finales de la época colonial e inicios de la Independencia" (Las tramas... 5-86) me detengo, por ejemplo, en una disputa legal que, muy poco tiempo después de instalada la imprenta en Caracas (1808), se refiere a los derechos de propiedad intelectual - "literaria", como se decía en ese momento. Es importante tener presente que una revisión minuciosa nos llevaría a encontrar otras discusiones por este motivo y no solo a propósito de lo que hoy entendemos por literatura. Así, para mencionar un solo ejemplo, José Luis Ramos, en la introducción de 1838 de su Silabario (un libro que ofrecía algunas novedades tipográficas para facilitar la enseñanza y el aprendizaje de la lectura), señala lo siguiente:

Después del año de 1829 (...) se han ejecutado hasta el presente diversas reimpresiones [del Silabario] por el Sr. Tomás Antero, pero tan desfiguradas y llenas de errores, como era preciso que sucediese, a causa de no haber contado dicho impresor conmigo para nada, ni obtenido mi consentimiento, en los términos que exigía la justicia, prevaliéndose de la circunstancia de que nuestros legisladores, a pesar del ejemplo de las demás naciones, no han expedido todavía la ley protectora de la más preciosa y sagrada de todas las propiedades, esto es, de las producciones literarias. (Ramos 69)

$\mathrm{Y}$ es que el siglo XIX se inaugura no solo con los movimientos a favor de la independencia, sino también con la introducción de la imprenta en muchos países hispanoamericanos. Poco después comenzarán a aparecer leyes, decretos o reglamentos sobre la libertad de imprenta. Sin embargo, las consecuencias de estos simples datos más que obvios no han sido revisadas con la atención que merecen. La imprenta durante la Primera República en Venezuela (abril 1810 - julio 1812) sirvió sobre todo para la publicación de periódicos, hojas volantes y "papeles", casi siempre al servicio de las causas a favor o en contra de la independencia, pero también brindó la ocasión para que algunos letrados comenzaran a pulsar sus posibilidades de subsistencia de cara a un público que empezaba a formarse como lector, en un número considerable, justamente con esos impresos y los que llegaban en gran cantidad del extranjero (las guerras de independencia, como 
se sabe, alentaron la circulación de escritos). No parece un desatino, entonces, tratar de indagar en los cambios que produjo la introducción de la imprenta $-\mathrm{y}$ del "capitalismo impreso", para usar los muy adecuados términos de Benedict Anderson-, más allá de los asuntos ligados a una concepción de la literatura que para esa época resulta estrecha, al menos inadecuada. La introducción de la imprenta significó para los letrados la posibilidad de dirigirse a unos lectores que ya existían en Venezuela, como dan cuenta los estudios de Ildefonso Leal y Elena Plaza sobre la circulación de impresos en el período colonial. A partir de ese momento, se impondrá un desarrollo complejo, en el que intervinieron muy diversos factores difíciles de ponderar en la actualidad. Me refiero al simultáneo proceso de profesionalización de los escritores y de formación de un público lector, en un contexto nada favorable para los primeros porque tendrán que competir con los impresos más prestigiosos y muchas veces más baratos que venían de Europa (baste pensar, sobre este punto, en el caso de los narradores de mediados de siglo, quienes necesitaron abrirse paso en medio de la avalancha de folletines que producían para la naciente industria cultural autores como Dumas y Sue - ficciones que se tradujeron con mucha rapidez en Venezuela para su publicación en los periódicos). Es revelador que el primero que hace uso de su pluma - y reciba una remuneración por ello - para publicar periódicamente en el taller instalado en Caracas en 1808 sea Andrés Bello. Este hecho, a pesar de lo importante que parece, no fue el que consideró Rama, por ejemplo, al estudiar los letrados latinoamericanos de esos años, razón por la cual terminó considerando que Fernández de Lizardi era una excepción en su afán de buscar y formar lectores ${ }^{2}$. Bello ha seguido siendo así, aparte de un objeto de culto o de rechazo, ambos excesivos, el nombre que sirve para dar coherencia a unas "obras" y no un escritor que supo abrirse camino en el nuevo y complejo sistema de intercambio que inauguraba la instalación de la imprenta en Caracas ${ }^{3}$.

2 Quizá el tono jocoso y resueltamente comercial sea lo que más asombre en la actualidad del "Prólogo, dedicatoria y advertencias a los lectores" que hace Fernández de Lizardi en el Periquillo Sarniento, como queda claro cuando dedica la novela no a un mecenas sino a los que pagarán por comprarla: "Esto es, oh serenísimos lectores, lo que yo hago al dedicaros esta pequeña obrita que os ofrezco como tributo debido a vuestros reales... méritos" (95). Pero la necesidad de conseguir lectores que paguen por la compra de periódicos, de impresos en general, la compartió con todos los escritores del siglo XIX.

3 Tal vez sea difícil comprender que escritores que suelen asociarse a posturas "conservadoras" sean los primeros en hacer uso de los avances tecnológicos, los primeros en percibir las ventajas que dan ciertos medios sin duda democratizadores, como ocurre con Bello y la imprenta, pero también en el siglo XX con Arturo Uslar Pietri y su temprano uso de la televisión. La historia de la cultura venezolana tiene el enorme atractivo y el inmenso reto de ofrecer problemas particular- 
No es mi intención señalar simplemente que deba trasladarse la época de interés a principios del siglo XIX, pues esto no sería más que correr el problema a unos años antes. Además, un examen del siglo XVIII con seguridad produciría muchas y muy gratas sorpresas - lo que debe incluir las islas del Caribe que, gracias a los movimientos de los buques, tenían un constante y muy intenso intercambio con las colonias españolas, lo que obligaría también a repensar el territorio a acotar en un trabajo que intente dar cuenta de la circulación de ideas y de impresos en ese período- - Hablar de una revolución en la lectura para la Venezuela de ese momento es, ciertamente, muy arriesgado, para no decir temerario; pero sí podría examinarse la intensa y cada vez más acelerada circulación de escritos y de información que se da especialmente a finales del siglo XVIII y principios del XIX -y, por supuesto, después. Se trata, entonces, de comprender que para revisar problemas como las prácticas de lectura y escritura o la formación de un público lector, se necesita pensar en procesos más largos, en los que muchas veces no se pueden hacer cortes tajantes ni tampoco pensar en una línea que se desplaza progresiva y necesariamente hacia el futuro. La introducción de la imprenta, por ejemplo, generó nuevas maneras de circulación de los escritos pero también produjo la reorganización de las que existían previamente, creando así modos de intercambio en los que se mezclan formas viejas y nuevas. Parece mejor, por tanto, entender estos procesos como de marcha lenta y vacilante, aunque pueda acelerarse en momentos específicos para después volver atrás, tomar un atajo o desviarse por otro camino. Resulta importante, por eso, no atenerse a las fechas que sirven para delimitar otros procesos, como es el caso de los cambios políticos ocurridos en esa época, ni imaginar el proceso como un indetenible camino hacia la madurez que permite la aparición de ciertas nociones "modernas". Como se verá, defender la propiedad "literaria", abogar por la "opinión pública", asumir un talante rebelde y crítico frente al poder o aprovechar y explotar las posibilidades que ofrece el "capitalismo impreso", son todos asuntos que podemos encontrar muy temprano, tanto como ese confuso y contradictorio período que marca el final de la época colonial y los comienzos de la independencia.

mente interesantes para el estudio de las relaciones entre el "capitalismo impreso" o la industria cultural y los muy respetables letrados consagrados después por las academias (Fermín Toro y el uso del folletín es otro ejemplo). También resulta interesante pensar en el acercamiento crítico, pero decidido y reivindicativo, de un escritor como José Ignacio Cabrujas, identificado con proyectos políticos de "izquierda", a productos de la industria cultural, como la telenovela, que eran entendidos en su momento por los sectores políticos a los que pertenecía como degradados y "alienantes". 
Rafael Gutiérrez Girardot (1988) se había referido a un problema semejante en sus trabajos sobre el intelectual cuando señalaba, a partir de los estudios de José Luis Romero, que era indispensable comprender el siglo XIX hispanoamericano como parte del proceso de estabilización de la sociedad burguesa - que puede remontarse al final de la Edad Media - y de disolución del Antiguo Régimen. Esta es también, aunque en otro sentido y en el campo de los estudios históricos, la perspectiva que adopta François-Xavier Guerra (Introducción a Los espacios públicos en Iberoamérica) en sus trabajos sobre la sociabilidad y los espacios públicos al considerar a España y sus colonias como parte del área cultural del Antiguo Régimen. Sin embargo, es importante advertir que no ha sido esta la mirada que ha predominado en los estudios literarios hispanoamericanos, pues en ellos el centro del debate lo ha ocupado el modernista fin de siglo, como ya señalé. De esta manera se ha construido una imagen según la cual el ingreso a la modernidad en Hispanoamérica se produce, casi de modo abrupto, en el mismo momento en que comienzan a insinuarse las propuestas estéticas modernistas. Parece así que "modernidad" suele confundirse con "modernización" y más específicamente con "urbanización" a una escala considerable, hecho que se produce a finales del siglo XIX en Latinoamérica, según José Luis Romero ${ }^{4}$.

Pero la introducción de ideas "modernas" e ilustradas puede remontarse al siglo XVIII y, lo que es más importante, estas ideas, y las transformaciones que se pueden asociar a ellas, produjeron cambios en las sociabilidades y en los valores que reivindicaban aquellos que comenzaron a vestirse a la moda, que jugaron a la innovación y a la rebeldía, así haya sido una simple pose (¿ino es también una

4 Arturo Almandoz estudia con detenimiento las representaciones ligadas al imaginario urbano en algunos escritores del siglo XX en La ciudad en el imaginario venezolano. Sobre la importancia de la ciudad en el imaginario hispanoamericano, desde la época de la conquista, debe consultarse el trabajo de J. L. Romero Latinoamérica: las ciudades y las ideas. De hecho, Romero señala que "fue la ciudad la que elaboró, desde su fundación misma, la imagen de la realidad circundante y el modelo operativo que guiaría la acción del grupo fundador" (68). Para este objetivo fue fundamental la representación de América como un "vacío" que había que llenar. La imagen que se impuso fue la de la fundación de una nueva Europa (de lo que dan cuenta los nombres de muchas ciudades y regiones: "Nueva España" es un buen ejemplo), a pesar de que era "en verdad, sólo frontera y periferia de la Europa vieja" (68). La conclusión de Romero sobre el ciclo de las fundaciones lleva a pensar en un espejismo urbano: "El ciclo de las fundaciones es, precisamente, el del dibujo del nuevo mapa del nuevo mundo, un mundo urbano e intercomunicado, como no lo había sido. Es, también, el de la primera ideología creada por ese mundo urbano: la que negaba la realidad de un mundo sociocultural inequívocamente existente para proponer la creación de otro nuevo según el modelo de las metrópolis" (68). Hace falta indagar un poco más en las consecuencias que tuvo en las manifestaciones culturales esa ideología urbana de los conquistadores y sus descendientes. 
pose la del dandy finisecular o la del afligido romántico de mediados de siglo?). Los documentos que revisa Elena Plaza ("Vicisitudes de un escaparate..." y "El miedo a la Ilustración...") para mostrar las medidas que tomaron las autoridades coloniales frente a esa "nueva raza de filósofos" que fueron los ilustrados y que perturbaba la pretendida tranquilidad de la sociedad colonial, no solo se refieren a libros sino también a modas, poses y actitudes que dejan ver que los libros se leyeron pero además se tradujeron en prácticas de la vida cotidiana, así fuera únicamente entre la élite. Por estos motivos, la pregunta que se formulara ya hace unos cuantos años Foucault, qué es un autor, no sólo debe responderse haciendo una revisión del discurso jurídico o, como vio Chartier ("Figuras del autor"), de la intervención decisiva y determinante de los impresores, sino además de las prácticas que están en juego en un momento dado, de las censuras y límites que impone una sociedad colonial o un período marcado por urgentes problemas políticos.

Contestar al interrogante qué es un autor (para no mencionar las otras posibilidades: letrado, intelectual, escritor, redactor, periodista) o qué es un lector (o "escucha", ya que los impresos también tenían receptores no alfabetizados) no resulta una tarea sencilla. Para el siglo XIX venezolano, hay que revisar las prácticas concretas, los significados que podía tener una palabra y el contexto en que tenían lugar los intercambios, y no partir de ideas preconcebidas que refuerzan la representación de una Venezuela siempre rural y aislada del resto del mundo. Suponer, por ejemplo, que lector es solo aquel que descifra un texto es dejar fuera una inmensa masa de receptores que pudieron tener acceso a los textos por otras vías y en quienes también estaban pensando los escritores. El escritor, por su parte, podía ser aquel encargado de organizar, resumir y dar coherencia a textos producidos por otros, como lo hacían Bello e Isnardy ${ }^{5}$ en La Gaceta de Caracas (Gazeta de Caracas en el original). En este sentido, Javier Lasarte destaca sobre el "siglo XIX estrecho" que ha construido la crítica que si "algo predomina en las representaciones académicas sobre la postindependencia es la figuración del letrado del XIX como un sujeto uniforme, rápidamente tipificado" (48). Por este motivo, he optado por examinar algunos casos concretos, referidos a momentos decisivos en la circulación de los impresos (la introducción de la imprenta, la apropiación de géneros modernos como el folletín o la adopción de técnicas de reproducción de imágenes), que permitan mostrar la complejidad de estos problemas y, espero, algunas vías para acercarse a ellos.

5 Como suele ocurrir con la ortografía del siglo XIX, el apellido puede aparecer de diversas maneras: Isnardy e Isnardi (emplearé la primera porque es la más usada en los documentos del siglo XIX). 
El concepto de "ciudad letrada", acuñado por Rama hace ya unos cuantos años (1984), es, sin dudas, uno de los que han conseguido mayor fortuna en los estudios sobre el siglo XIX latinoamericano ${ }^{6}$. Fue el resultado de un enorme esfuerzo realizado por el investigador uruguayo para la comprensión de la función de los escritores y de la(s) letra(s) en América Latina desde el período colonial. En un intento semejante, las generalizaciones podrían parecer necesarias, pues de otro modo se correría el riesgo de no poder sintetizar para marcar las tendencias más importantes. Sin embargo, una revisión más detallada nos muestra que la forma que adopta la ciudad letrada en las décadas posteriores a la Independencia - la "ciudad escrituraria" - , resulta insuficiente, sobre todo si consideramos los proyectos más amplios en los que surgieron muchos de los trabajos de los letrados ${ }^{7}$. Me refiero a las asociaciones y a las empresas periodísticas, como la Gaceta de Caracas, el Liceo Venezolano y, mucho más tarde, El Cojo Ilustrado, que buscaron ampliar el circuito letrado apelando a múltiples estrategias, como la apropiación del folletín o el uso de la imagen.

A partir del trabajo de Rama, hemos acusado a la ciudad letrada del siglo XIX de nada menos que de ser letrada. Pero, aparte de la contradicción (no necesariamente importante), habría que preguntarse cuán letrada fue en realidad. Parece que al acoger el concepto no se discutió lo suficiente sobre un problema crucial: quién construyó el objeto, además de cuándo y cómo. Metodológicamente podría haber un círculo vicioso: estudiamos al letrado y sus obras y al hacerlo lo desconectamos de los proyectos que dieron sentido a sus trabajos, de los esfuerzos que realizaron para aprovechar los medios democratizadores que ponía a su alcance el "capitalismo impreso". Extraemos, casi bisturí en mano, las "obras" de los periódicos y revistas que fundaron o respaldaron con sus colaboraciones y al mismo tiempo los cuestionamos por vivir de espaldas a la ciudad "real". De este modo no consideramos las nuevas sociabilidades y los nuevos espacios para el intercambio que ayudaron a construir, lo que para muchos de ellos fue una parte esencial de los proyectos, sin duda ilustrados, que sostenían.

6 Para Rama, la "ciudad letrada", tanto en la colonia como en el temprano período republicano, está compuesta fundamentalmente de "escribanos, hacedores de contratos y testamentos, quienes disponían de la autoridad que transmitía la legitimidad de la propiedad" (51). Al tener el domino exclusivo de la letra, terminaron por sacralizarla, reforzando así el poder de la burocracia colonial y post-independentista.

7 Rama emplea esta denominación para subrayar la diferencia entre una élite letrada, que rinde culto a la escritura y a la norma lingüística metropolitana, y una población analfabeta, cuya lengua es "popular y cotidiana" (52). 
No olvidemos, en este sentido, que el propósito de formar ciudadanos y, por tanto, de alfabetizar a la población, atravesó el siglo. En la década del 20, por ejemplo, Joseph Lancaster, el famoso pedagogo inglés, fue contratado por Bolívar para que introdujera su novedoso sistema educativo en Caracas - este método, llamado de "enseñanza mutua", presentaba el enorme atractivo de multiplicar, con mayor rapidez que cualquier otro, el número de personas alfabetizadas. Aunque fueron proyectos muy contradictorios y que marcaron claras exclusiones, no puede dejarse de lado que muchas veces se unieron a empresas comerciales que necesitaban crear un público amplio, no restringido a las élites, o nuevos consumidores (solemos creer que el consumismo es un fenómeno del siglo XX - a pesar de los muchos artículos de costumbres y ensayos realizados por los letrados para combatirlo - o que se refiere sobre todo a objetos de lujo y no a impresos, como es el caso del folletín). Pensemos, además, que el éxito de una revista o periódico dependía, indudablemente, del número de lectoresconsumidores dispuestos a pagar.

Tal vez esta perspectiva que separa de un modo tajante a la cultura oral de esa amurallada "ciudad letrada" sea deudora de la mirada según la cual las sociedades decimonónicas - y, por consiguiente, las culturas latinoamericanasestaban claramente divididas entre una oligarquía muchas veces inescrupulosa y un pueblo marcado por el analfabetismo, fácil presa de las manipulaciones de la primera. Se olvida así, entre otros aspectos, el crecimiento de nuevos sectores y la democratización (relativa, ciertamente) que este acarreó. Y es que seguimos pensando el siglo XIX a partir de las representaciones construidas por los positivistas, para quienes romper con el pasado inmediato, ruralizarlo o barbarizarlo (la más adecuada manera de desprestigiarlo de acuerdo a sus propias apuestas por la civilización), sirvió como estrategia para legitimar el presente ${ }^{8}$. No examinamos el

8 Es el caso de esa imagen de una Venezuela polvorienta, atrasada y aislada del resto del mundo, que únicamente logra ponerse en pie con el empuje dado al proceso de modernización por Guzmán Blanco y el liberalismo amarillo. Es una representación que parece más el fruto de los esfuerzos de los historiadores positivistas de finales del XIX y principios del XX que producto de un análisis más o menos riguroso. Esta observación, que ya la han realizado historiadores como Elías Pino Iturrieta, tal vez nos permita comprender uno de los rasgos de nuestra manera de construir el pasado y nuestra imagen como nación: esa manía fundacional, por así llamarla, que desacredita y cancela el pasado una y otra vez para prometer un futuro mejor, comenzando casi desde cero o remontándonos a los "orígenes". Uno de los rasgos más claros de esa obsesión es considerar que solo es rescatable el pasado heroico, el de la independencia, con sus mártires siempre traicionados por las generaciones siguientes, figuras necesarias para levantar el prestigioso panteón nacional donde pronto podrán incluirse los protagonistas de la nueva empresa fundacional que los declara sus antecesores. 
otro lado de esa imagen de una Venezuela atravesada por montoneras y hombres de a caballo, como la relación entre ciudadano y consumidor que propone abierta y descarnadamente el "capitalismo impreso". Evitamos así las contradicciones que hacen posible la coexistencia de formas que remiten a la oralidad y géneros modernos de masa, como ocurre en el folletín Los Mártires de Fermín Toro, o las paradójicas manifestaciones que se dan cita en el periódico La Gaceta de Caracas, esto es, en el medio moderno por excelencia.

Como intento explicar en "Lectores de folletín en El Liceo Venezolano: nuevos lectores en la República de las Letras" (Las tramas... 87-128), esa representación que divide de manera maniquea entre la élite y el pueblo (muchas veces presentada como una oposición entre victimario y víctima) puede rastrearse en muchos discursos del siglo XIX, especialmente en los folletines ${ }^{9}$. Forma parte de lo que Brooks ha llamado la "imaginación melodramática" y sirvió para construir las representaciones del pueblo. Como muestran algunos estudios, este elemento tan importante para la imaginación moderna invadió no solo los folletines sino también el discurso político y el jurídico. Por otra parte, los intercambios entre la cultura letrada y los sectores pensados al margen han sido objeto de muchas revisiones en los últimos tiempos. La imagen de dos culturas incomunicadas, una oral y otra letrada, ha mostrado ser insuficiente para dar cuenta de la compleja red de circulación de los escritos, aun en sociedades con altos índices de analfabetismo. En este sentido, los estudios sobre la lectura destacan que no hay un abismo insalvable entre oralidad y escritura, sino por el contrario relaciones muy ricas que todavía están por explorarse. Asimismo, estas investigaciones han mostrado que la separación entre alfabetizados y no alfabetizados no se corresponde con las divisiones de clase que han servido a las historias tradicionales para compartimentar a partir de ellas las prácticas sociales y culturales. Algunos investigadores han sacado a la luz unos cuantos lectores - muchas veces asiduos y con frecuencia también expertos- que no formaban parte de las élites ni de los sectores tenidos por instruidos o alfabetizados. De hecho, estos trabajos han

9 Los términos que emplea Rama para describir la situación de la "ciudad escrituraria" pueden servir como ejemplo de esta oposición irreconciliable que señalo: "La ciudad escrituraria estaba rodeada de dos anillos, lingüistica y socialmente enemigos, a los que pertenecía la inmensa mayoría de la población" (53, las cursivas son mías). El primer anillo lo constituía "la plebe formada de criollos, ibéricos desclasados, extranjeros, libertos, mulatos, zambos, mestizos y todas las variadas castas derivadas de cruces étnicos que no se identificaban ni con los indios ni con los negros esclavos" (53). Como puede suponerse, el segundo estaba compuesto por indios o por negros esclavos. Para Rama, no hay comunicación entre esos anillos y la ciudad escrituraria, dado que la función del letrado es justamente levantar un "cerco defensivo respecto a un entorno hostil y, sobre todo, inferior" (54). 
demostrado que la alfabetización no se llevaba a cabo de manera semejante a como se hace hoy en día, pues escribir, leer y contar eran destrezas aprendidas de manera independiente. Por este motivo la capacidad de firmar ya no se puede tener por índice de alfabetización, como lo establecían los estudios históricos hasta hace unas décadas, pues se podía saber leer pero no firmar o, por el contrario, se podía saber firmar pero no leer.

Muchas veces se ha dicho que la fuente principal para el estudio del siglo XIX la constituyen los periódicos. No solo los problemas confrontados para la publicación de libros en esa época llevan a esta conclusión: la empresa periodística fue entendida por los letrados como una manera de ejercer la ciudadanía, de participar en la cosa pública. En periódicos y revistas emprendieron una campaña para la formación de la opinión pública y el adiestramiento de nuevos lectores en países en los que el analfabetismo parecía la norma, y de este rasgo estaban muy conscientes. Es por la importancia que tiene el periodismo durante el siglo XIX - hecho que Rama supo ver con claridad en su estudio sobre Rubén Darío pero no así en La ciudad letrada-, que mis investigaciones se detienen en las páginas mismas de las revistas y periódicos, evitando (en la medida de mis posibilidades) purificar los textos de las huellas que dejaron los proyectos e intereses de los letrados coetáneos y las reducciones y "purgas" que hicieron los posteriores. Como explico en "Leer una revista ilustrada o una rápida visita a un moderno museo portátil" (Las tramas... 129-192), esa representación de la cultura del siglo XIX como exclusivamente dedicada a las letras es producto del proceso de autonomización de la literatura y de su identificación con las Bellas Letras (para lo cual se requería pasar por alto los elementos espurios que remiten al intercambio comercial). Es por este motivo que El Cojo Ilustrado ha sido entendido como el "órgano continental" del modernismo y no como una empresa comercial interesada en las nuevas técnicas de reproducción de imágenes -el trabajo de Mirla Alcibíades ("El Cojo Ilustrado...") sobre esta revista es una excepción en este sentido.

Por esta razón, la importancia otorgada a la letra - y a las Letras - en $E l$ Cojo Ilustrado no debe confundirse con el proceso que llevó a la crítica a eliminar los muchos intereses (incluso comerciales) que le dieron origen, y de manera especial aquellos vinculados con la relevancia que cobra la imagen - a través de la reproducción de dibujos, pinturas o fotografías- en ese fin de siglo. Esa fue una época en la que la imagen visual - de las publicaciones periódicas, las tarjetas postales o de las grandes exposiciones - se coloca en el centro de muchas prácticas e intercambios sociales y culturales. Los letrados hispanoamericanos se valieron de las nuevas propuestas que pusieron a su alcance las novedosas técnicas 
de reproducción en masa, tanto de textos como de imágenes, y adaptaron viejas estrategias usadas en rituales patrióticos, en los que la imagen (retratos u objetos de Bolívar, por ejemplo) tenía un papel protagónico.

Con relación al libro, debo decir que el siglo XIX ha sido considerado la época de oro de los libros ilustrados - también, es bueno recordarlo, de la caricatura que, como se sabe, invadió los periódicos a ambos lados del Atlántico. Muchas autores trabajaron mano a mano con los dibujantes, como lo muestran las novelas de Julio Verne o de Charles Dickens, pero también El Periquillo Sarniento, publicado en sus primeras ediciones con ilustraciones y con fórmulas tipográficas que en la historia remitían a las imágenes, que curiosamente han desaparecido de las ediciones actuales, incluso de las más prestigiosas como la realizada por Cátedra (1997). Sorprende en esta edición la contradictoria explicación sobre la borradura de las cursivas que en la novela de Lizardi remitían a las imágenes: "Hemos procurado respetar al máximo las cursivas, aunque hemos eliminado las que constituyen una llamada para que el lector se fije en las ilustraciones Lizardi, como buen espíritu ilustrado, sabía del poder didáctico de la imagen, aparte del atractivo que ello suponía en el momento de la venta" (Fernández de Lizardi 61). Sorprende porque la editora, Carmen Ruíz Barrionuevo, explica con mucha razón que Lizardi comprendía el poder de la imagen. Del mismo modo, la traducción hecha en Caracas en 1845 de la novela de Eugène Sue Los Misterios de París llevaba también imágenes (publicada apenas un año después de la edición "corregida y reformada por el autor" hecha en París, como señala el propio libro) ${ }^{10}$. Lamentablemente es poco lo que puede decirse sobre este volumen porque el único ejemplar sobreviviente se perdió en las estanterías de la Biblioteca Nacional (un asunto ligado a las fuentes y a la construcción del "archivo de la memoria nacional" que no podré atender en esta ocasión: por qué se conservan ciertos impresos y otros no $)^{11}$. Contamos, hasta donde he podido indagar, solo con una imagen que Humberto Cuenca en 1980 reprodujo en su libro Imagen literaria del periodismo (fig. 1). Así mismo, hacia mediados de siglo se hicieron

10 Los datos los tomo del trabajo de C. R. Villasana, ya que no he podido revisar el libro.

11 En el capítulo "Lectores de folletín en El Liceo Venezolano..." (Las tramas... 87-128) señalo que los estudios literarios despreciaron hasta hace poco muchas novelas venezolanas del siglo XIX, como Los Mártires de Toro, por tener elementos folletinescos y melodramáticos. Tal vez en este caso el asunto se agrave porque se trata de una traducción de un folletín —nada menos que uno de los éxitos más importantes de la industria cultural del siglo XIX - que inserta imágenes para atraer a un público más amplio. Según Ramón de la Plaza (Ensayos sobre el arte en Venezuela $\mathbf{x x}$ ), las imágenes fueron producto de la pluma de Gerónimo Martínez, esto es, un dibujante que también se valió de las posibilidades que le brindaba el negocio de la imprenta. (192-197) 
los primeros esfuerzos por presentar lo que podríamos llamar "álbumes de la nación", esto es, impresos ilustrados que, como el Museo Venezolano, aprovecharon las técnicas de reproducción de grabados para entregar representaciones de la nación venezolana. De este modo podemos constatar que para la representación del circuito letrado del siglo XIX como una atrincherada ciudad escrituraria ha intervenido una purga realizada en el siglo XX que la despojó de esos elementos supuestamente ilegítimos, y sin dudas no compatibles con la idea de las "Letras" que se afianzó después.

Finalmente, en "Lecturas de mujeres: imágenes en femenino de la 'epidemia lectora" (Las tramas... 193-238) intento rastrear algunas huellas dejadas por las discusiones en torno a las supuestas consecuencias perniciosas de la lectura, casi siempre referidas a los nuevos sectores que se incorporaban de manera sostenida al circuito de los impresos, para lo cual me valgo precisamente de imágenes que aparecieron en El Cojo Ilustrado. Reviso en él algunas representaciones de las lectoras, muchas veces centro de esos debates, que deben considerarse como parte de los "datos" a tomar en cuenta en una discusión sobre la "revolución de la lectura" o la "epidemia lectora"12. Estudio, por tanto, algunas escenas de lectura y referencias a los lectores aparecidas en ficciones latinoamericanas y venezolanas, así como reproducciones de pinturas y fotografías realizadas por $E l$ Cojo Ilustrado. Asimismo, examino las tensas relaciones entre imágenes visuales y textos (leyendas o comentarios), ese cruce tan fructífero que explotaron ampliamente las muchas publicaciones ilustradas de esa época, para comprender las "lecturas" que casi siempre en forma de relato buscan dar sentido, imponer una interpretación, a las imágenes visuales. Este recorrido me permite mostrar una situación muy compleja con respecto a los intercambios letrados, dado que formas tradicionales de lectura pensadas, por ejemplo, para la recitación (y que suponen,

12 A veces resulta difícil comprender a quién respondían los letrados del siglo XIX cuando se referían a la importancia de la novela en la creación de un público lector. Es el caso de Sarmiento, por ejemplo, cuando en "Las novelas" se refiere a la "escuela del Orden" que se niega a que se use el "azúcar" de la ficción para atraer y formar nuevos lectores (1856, en Los novelistas como críticos 25). Me parece importante advertir que muchos de ellos parecen responder a la Iglesia, un sector con mucho peso en la sociedad del siglo XIX, pero que no se suele considerar a la hora de dar cuenta de las polémicas y discusiones en las que participaron los letrados, pues tendemos a imaginar la ciudad letrada como compuesta solo de escritores en el sentido actual, olvidando así a los grandes oradores y escritores eclesiásticos que tanto peso y prestigio tuvieron en ese entonces. Se trata de un estudio que está por hacerse y que obliga a la revisión de fuentes distintas a los libros, periódicos y revistas producidos por los "autores" que reconocemos en la actualidad. Para citar un solo ejemplo, en la primera entrega (1855) del periódico Crónica Eclesiástica de Venezuela aparece un artículo titulado justamente "Peligros de la lectura de las novelas" (134). 
como se verá, una "semiotización" del cuerpo, especialmente del femenino), se combinan con modos de lectura considerados "modernos", en imágenes y textos que parecen apuntar a una ansiedad, un temor, con respecto a la lectura de sectores que, como las mujeres, comienzan a adoptar nuevas relaciones con los libros, o son convocados a participar, de muy distintas maneras, en nuevas formas de intercambio.

He considerado indispensable revisar las prácticas y propuestas que surgieron efectivamente en Venezuela, con el fin de no partir de las generalizaciones que acarrean las categorías de "latinoamericano" e "hispanoamericano", casi siempre pensadas para los países y autores más conocidos o prestigiosos en la academia. Busco de este modo evitar las reducciones que han terminado por entregar una representación del letrado hispanoamericano del siglo XIX construida a partir de los "autores" más conocidos - y hasta injusta, por estereotipada, con esos mismos escritores. Es precisamente este problema el que señala Javier Lasarte como uno de los productos de ese "XIX estrecho" que se ha impuesto en los estudios académicos:

Como he querido mostrar, las lecturas reductivas sobre la primera mitad del siglo XIX han venido construyendo un modelo (anti)paradigmático del intelectual de ese período que, además, ha servido para denominar al siglo en su conjunto. Por las razones que sea, quienes han recibido el favor de esa construcción de representatividad son mayormente los pensadores de Argentina - generación del 37 y alrededores - y, en menor medida, los equivalentes de Chile. (2003 58)

Esto no quiere decir, por supuesto, que mis estudios propongan aislar los "casos" venezolanos del resto del continente, desconectándolos de propuestas semejantes surgidas en otros países, pues es también mi intención destacar que algunos de estos asuntos estaban siendo abordados en un contexto más amplio (no solo latinoamericano, por cierto). La proposición ha sido, fundamentalmente, mostrar problemas concretos que permiten repensar algunos presupuestos básicos en los estudios sobre el siglo XIX y señalar al mismo tiempo algunas vías que creo fructíferas para su mejor comprensión. No busco, por tanto, historiar las prácticas de lectura y escritura, ni dar cuenta de manera meticulosa de las complejas redes de circulación de los escritos. Tampoco entregar una historia del simultáneo proceso de profesionalización de los escritores y de formación de un público moderno. Me limito a detenerme en algunos textos e imágenes que consideré especialmente relevantes para hacer algunas preguntas, que no necesariamente tienen respuestas, con respecto a algunos puntos que creí centrales 
de esos muy complejos y contradictorios procesos. De este modo también quise proponer que para el estudio de estos problemas no solo debe acudirse a los "textos" escritos que hemos entresacado escrupulosamente de los periódicos, revistas, libros y proyectos "ilustrados" del siglo XIX, sino que contrariamente a lo que dice Darnton en el sentido de que en "este tipo de historia, por rigurosa que sea su teoría, se carece desgraciadamente de fuentes" (2003 439), las fuentes pueden encontrarse en muchos partes, si se busca con cuidado y con una mirada que no intente purificarlas.

No quisiera cerrar estas líneas sin recordar que hay en la historia de los escritos un doble proceso que debe ser considerado: por un lado una tendencia a la secularización y democratización, relacionada con las nuevas técnicas que se introducen y que ponen los impresos en manos de un mayor número de personas; y, simultáneamente, una nueva sacralización del libro, hecho que puede seguirse en la actualidad con el impacto que ha producido internet. Como señala Derrida en Papel máquina (23) es como si cada etapa, en una transformación técnica, pareciese destinada a desacralizar, a democratizar, a secularizar, a desfetichizar a los largo de una interminable historia de la Luces o de la Razón (antes y más allá de la Aufklärung); pero como si, no obstante, cada etapa llevase consigo, de una manera asimismo ineludible, una reinvestidura sacra o religiosa.

Con seguridad, al estudiar el siglo XIX hemos puesto más énfasis en los resultados de la sacralización del libro, así como del "autor" y sus "obras", muy importantes en esa gran empresa que se propuso esa época: la creación de una "literatura nacional"; y olvidamos la otra cara del problema: el proceso de secularización y democratización que acarreó la introducción de la imprenta a principios de siglo y la proliferación de impresos de diversos tipos a lo largo de la centuria. Por este motivo considero que los estudios que realizo de momentos que creí decisivos conducen a plantear la necesidad de repensar el impacto producido por el "capitalismo impreso" y la industria cultural en la cultura del siglo XIX. 


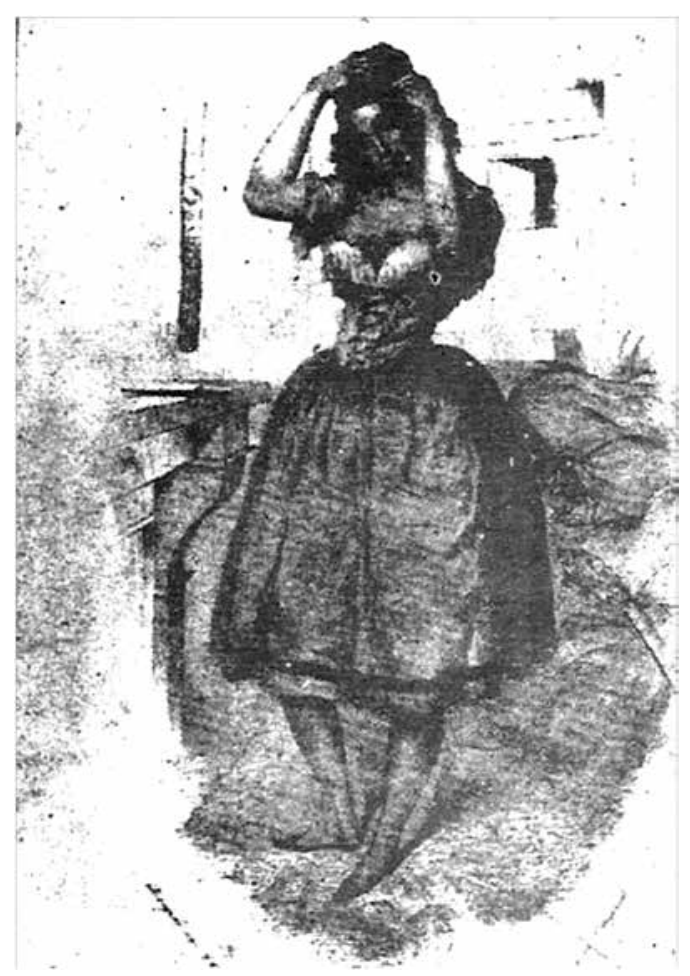

Fig. 1. Ilustración de la edición caraqueña de Los Misterios de París (1845). Cuenca, Humberto. Imagen literaria del periodismo. Caracas: Universidad Central de Venezuela, 1980. 113. Impreso.

\section{Obras citadas}

Alcibíades, Mirla. "El Cojo Ilustrado en el proceso de la modernidad en Venezuela".

Tesis. Universidad Simón Bolívar como requisito para optar al título de Magíster en Literatura Latinoamericana. Caracas, 1993. Impreso.

Almandoz, Arturo. La ciudad en el imaginario urbano venezolano. Caracas: Fundación para la Cultura Urbana, 2002. Impreso.

Anderson, Benedict. Comunidades imaginadas: reflexiones sobre el origen y la difusión del nacionalismo. México: Fondo de Cultura Económica, 1993. Impreso. (1 ${ }^{\mathrm{a}}$ edición en inglés de 1983).

Brooks, Peter. The Melodramatic Imagination. New Haven/Londres: Yale University Press, 1995. Impreso. ( $1^{a}$ edición: 1976).

Catelli, Nora. Testimonios tangibles: pasión y extinción de la lectura en la narrativa moderna. Barcelona: Anagrama, 2001. Impreso. 
Chartier, Roger. Entre poder y placer: cultura escrita y literatura en la Edad Moderna. Madrid: Cátedra, 200o. Impreso.

"Figuras del autor". El orden de los libros. $2^{\text {a }}$ edición. Barcelona: Gedisa, 1996. Impreso.

"Lecturas y lectores 'populares' desde el Renacimiento hasta la época clásica". Historia de la lectura en el mundo occidental. Eds. Guglielmo Cavallo y Roger Chartier. Madrid: Taurus, 1998. 413-434. Impreso.

Cuenca, Humberto. Imagen literaria del periodismo. Caracas: Universidad Central de Venezuela, 1980. Impreso.

Darnton, Robert. "Historia de la lectura". Burke, Peter, et al. Formas de hacer historia. Madrid: Alianza, 1993. 177-208. Impreso.

__ El coloquio de los lectores. México: Fondo de Cultura Económica, 2003. Impreso.

De Certeau, Michel. La escritura de la historia. México: Universidad Iberoamericana, 1985. Impreso.

"Leer: una cacería furtiva". La invención de lo cotidiano. I: Artes de hacer. México: Universidad Iberoamericana, 1996. 177-89. Impreso.

Derrida, Jacques. Papel máquina: la cinta de máquina de escribir y otras respuestas. Madrid: Trotta, 2003. Impreso.

Fernández de Lizardi, José Joaquín. El Periquillo Sarniento. Madrid: Cátedra, 1997. Impreso.

Foucault, Michel. “¿Qué es un autor?”. Dialéctica IX.16 (1984): 124-142. Impreso.

Gazeta de Caracas. Caracas: Imprenta de Gallagher y Lamb. Impreso. Octubre 2014.

Los primeros números pueden consultarse en http://www.cervantesvirtual.com/ partes/240350/gazeta-de-caracas

Introducción. Guerra, F-X., et al. Los espacios públicos en Iberoamérica:

ambigüedades y problemas. Siglos XVIII-XIX. México: Fondo de Cultura Económica, 1998. 5-24. Impreso.

Gutiérrez Girardot, Rafael. Modernismo. Barcelona: Montesinos, 1988. Impreso.

Historia de la edición y de la lectura en España: 1472-1914. Eds. Jean-François Botrel, Víctor Infantes y François López. Madrid: Fundación Germán Sánchez Ruipérez, 2003. Impreso.

Historia de la lectura en el mundo occidental. Eds. Guglielmo Cavallo y Roger Chartier. Madrid: Taurus, 1998. Impreso.

Historia de la lectura en México. México: El Colegio de México, 2000. Impreso. (1 ${ }^{\mathrm{a}}$ edición: 1988).

Lasarte, Javier. "El XIX estrecho: leer los proyectos fundacionales". Schmidt-Welle, Friedhelm. Ficciones y silencios fundacionales: literaturas y culturas postcoloniales en América Latina (siglo XIX). Madrid: Iberoamericana-Vervuert, 2003. Impreso. 
Leal, Ildefonso. Libros y bibliotecas en Venezuela colonial: 1633-1767. Caracas: Ediciones de la Facultad de Humanidades y Educación, 1979. Impreso.

Lyons, Martin. "Los nuevos lectores del siglo XIX: Mujeres, niños y obreros". Historia de la lectura en el mundo occidental. Eds. Guglielmo Cavallo y Roger Chartier.

Madrid: Taurus, 1998. 473-517. Impreso.

Los novelistas como críticos. Comps. Norma Klahn y Wilfrido H. Corral. México: Fondo de Cultura Económica, 1991. Impreso.

Monterroso, Augusto. Pájaros de Hispanoamérica. México: Alfaguara, 2002. Impreso.

Pino Iturrieta, Elías. País archipiélago: Venezuela, 1830-1858. Caracas: Fundación Bigott, 2001. Impreso.

Plaza, Elena. "Vicisitudes de un escaparate de cedro con libros prohibidos (actividades del Tribunal de la Inquisición en la Provincia de Caracas, 1778-1821)". Politeia 13. (1989): 331-36o. Impreso.

_El miedo a la Ilustración en la Provincia de Caracas (1790-1810)". Politeia 14 (1990): 311-348. Impreso.

Plaza, Ramón de la. Ensayos sobre el arte en Venezuela. Caracas: Imprenta La Opinión Nacional, 1883. Impreso.

Poblete, Juan. Literatura chilena del siglo XIX: entre públicos lectores y figuras autoriales. Santiago de Chile: Cuarto Propio, 2003. Impreso.

Rama, Ángel. La ciudad letrada. Montevideo: Fundación Ángel Rama, 1984. Impreso.

Ramos, José Luis. Fosé Luis Ramos. Estudio preliminar de Luis Beltrán Guerrero. Caracas: Italgráfica, 1961. Impreso.

Romero, José Luis. Latinoamérica: las ciudades y las ideas. Buenos Aires, Siglo XXI, 1986 (1ª edición México: 1976). Impreso.

"Peligros de la lectura de las novelas". Crónica Eclesiástica de Venezuela. 1 (14 de marzo de 1855): 134. Impreso.

Una vasta morada de enmascarados: poesía, cultura y modernización en Venezuela a finales del siglo XIX. Caracas: La Casa de Bello, 1993. Impreso.

Toro, Fermín. "Los Mártires". Fermín Toro. Caracas: Colección Clásicos Venezolanos de la Academia de la Lengua, 1963. Impreso. 70-130. Publicada por entregas en $\mathrm{El}$ Liceo Venezolano nos. 2, 3, 4, 5, 6 y 7 (1842).

Villasana, Carlos Raúl. Ensayo de un repertorio bibliográfico venezolano (años 18081950). Caracas: Banco Central de Venezuela, 1979. Impreso.

Wittmann, Reinhardt. “ ¿Hubo una revolución en la lectura a finales del siglo XVIII?". Historia de la lectura en el mundo occidental. Eds. Guglielmo Cavallo y Roger Chartier. Madrid: Taurus, 1998. Impreso. 435-472.

Zanetti, Susana. La dorada garra de la lectura: lectoras y lectores de novela en América Latina. Rosario: Beatriz Viterbo, 2002. Impreso. 